\title{
Embodied Online Activism: Breastfeeding Activism (Lactivism) on Facebook
}

\author{
LULA MECINSKA, Lancaster University, University of Cumbria
}

\begin{abstract}
Online support communities for people with various health problems and related online activist groups have been the focus of scholarly attention for three decades. The arrival of social media increased the popularity and breadth of both phenomena. Breastfeeding online activism represents an interesting case in how it connects the (health) support and activist online presences of breastfeeding women. Furthermore, breastfeeding activism - or lactivism - is a form of embodied activism, often performed through breastfeeding. Stemming from over six years of observant participation in breastfeeding spaces online, this article traces the ways in which lactivists use Facebook to further their cause. From the creation of support groups, through the use of Facebook capabilities to organise action and create structures, to Facebookspecific forms of mass action, including image flooding and negrating, I argue that the emergence of lactivism as we know it is intimately connected with, and through, the medium.
\end{abstract}

\section{KEYWORDS}

breastfeeding, activism, embodiment, social media, lactivism

Lactivism can be defined as practices of embodied breastfeeding activism carried out by breastfeeding women and enacted through breastfeeding (Stearns 2014). Breastfeeding itself, is a 'daily pattern of embodied living' (Hausman 2004, 278) and an 'embodied form of caregiving' (277), affected by the social structures and forms of consciousness which shape it as a practice, as well as the material and semiotic gendered realities of breastfeeding bodies. Breastfeeding parents ${ }^{5}$ engagements online are complex affairs through which breastfeeding bodies are 'translated' into online embodiment, where bodily, technological, reflexive and social aspects are intertwined (Rudnicki 2017). The embodied lactivist 'selves' who engage on

\footnotetext{
${ }^{5}$ Throughout this paper I am primarily talking about breastfeeding/women/mothers, but where possible aim to use more gender-neutral language in recognition of the reality of nursing parents who do not identify as woman/female/mother. This is not always possible as some forms of activism are specifically dealing with the oppressive structures of patriarchy and their effects on women's bodies.
} 
and offline are not separable. Nor can they be separated from the activities of exchanging advice, information, support, and knowledge within Facebook groups and on various 'walls', and ever stricter policy of personal pages being those of 'real people', insistence on real names, pictures and other 'authentic' data about oneself, but also the growing number of body tracking and multimedia functions Facebook contains. This paper argues that lactivism as we know it is intimately intertwined with the possibilities offered by online environments. It seeks to trace the ways in which lactivists are making use of possibilities offered by networked publics (boyd 2010), and more precisely, of the specific affordances of the interactive social platform of Facebook. This work stems from over six years of 'observant participation' (Moeran 2007) in lactivist and breastfeeding support groups and insider activist research (Mecinska 2018), and follows Stearns' (2014) injunction to study emergent forms of embodied breastfeeding activism (lactivism) enabled by online environments.

\section{From private to global to digital mundane: a brief overview of lactivist history}

The story of the breastfeeding movement parallels that of other embodied health movements (EHM), defined by Brown et al. (2004) as social movements addressing health issues by challenging scientific models and problems caused by oversight of the health issue. Like the breastfeeding movement challenging the 'bottle preference' of HCPs (Van Esterik 1989, Palmer 2009), EHMs challenge the established practices and knowledge from 'an embodied experiential perspective' of their participants (Brown et al. 2004, 54). Such formations have been the focus of scholarly attention as part of the broader interest in health social movements and patient groups. In most studies attention was focused on institutionalised actors, such as NGOs, patient coalitions, and groups which impact policy-making (Epstein 2008). The full 'organisational continuum', which according to the sociologist Kira Landzelius contains also 'quasi-organised, loose networks' organised by activists and increasingly appearing in online environments as virtual communities 'imagineered into existence...by cyber-activists' (2006, 532-3) is still being charted.

When the first women's breastfeeding support group was founded in 1956, breastfeeding was very much a 'private' issue (Weiner 1994, Tomori 2014, Van Esterik 1989, Hausman 2003). Over the course of the next 30 years it has become not only a public issue, but a global one, coinciding with public health goals of governments and transnational organisations, and culminating in policy-changing global initiatives (WHO 1981, Greiner 2000). Since that time, a movement coalesced around breastfeeding, grouping many actors - not all of whom can be said to represent the interests of women (Labbok 2015, Kedrowski 2010, Faircloth 2013). One of the ways this movement acts is by supporting parents who wish to breastfeed providing them 
with information, knowledge and resources. This can take different organisational forms, from multimedia information hubs to running community support groups. The organisation whose creation in the US is often taken as the starting point of the movement, La Leche League (LLL), works through its established multimedia presence to disseminate findings of research and publications on breast/chest-feeding (LLLI 2012, Hausman 2003, Faircloth 2013, Torres 2014). It operates internationally through national chapters and local groups run by accredited LLL leaders (Weiner 1994, Tomori 2014, Torres 2014, Faircloth 2013). Organisations of similar scope but more localised character are present in many countries; in the UK the Association of Breastfeeding Mothers, the Breastfeeding Network, and National Childbirth Trust engage in publications, research and support, delivering services with the local NHS trusts, and lobbying Parliament and other institutions.

Grass-roots breastfeeding support used to be understood and studied as face-to-face support groups based on formal and informal peer support (Dowling 2014, Faircloth 2013, Aiken and Thomson 2013). Over the last ten years, with a growing importance of mediatised sociability and the creation of 'digital mundane' practices of daily interactions and constant connectivity (Maltby and Thornham 2016, Wilson and Chivers Yochim 2017), a new form of grass-roots mobilisation has emerged. Research observes that connectivity is changing the ways in which women develop competencies in mothering practices, including breastfeeding (Romano 2007; McDaniel et al. 2011, Huberty et al. 2013, Fredriksen et al. 2016, Leune and Nizard 2012, Radkowska-Walkowicz 2009, Zdrojewska-Zywiecka 2012). Studies on parents involved in patient groups online (Akrich 2010, Schaffer et al. 2008) offer important insights into how online spaces facilitate information sharing and knowledge building and foster social support often leading to mobilization and activism around the health issue. Breastfeeding activism online parallels many of those forms of organising and sharing (Mecinska 2018). As Kate Boyer observes, new forms of activism in support of breastfeeding 'can be seen as emerging out of the magnitude of research highlighting the unique benefits of breast milk', including the social and economic importance of the practice, easily shared online, and may be facilitated 'by the ability to use the internet to organise' $(2011,431)$.

\section{Lactivism and breastfeeding: embodiment online}

My research engagement with the breastfeeding online community and participation in lactivist online groups is inextricably intertwined with over six years of embodied practice of breastfeeding two children to natural term. I therefore occupy a complex position of researcheras-informant (Hine 2000, 2015), one on which I reflect elsewhere (Mecinska 2018), but which allows for a rich, ethnographic engagement with lactivism off and online. This paper, 
specifically, traces some lactivist strategies and practices, arising from observant participation in Polish, UK and international breastfeeding support groups on Facebook. These groups vary in size, from several hundred to over twenty thousand members (Mecinska 2018). Throughout the process I strived to remain open about my research and consulted with fellow activist continuously. Due to varying levels of 'secrecy' of the groups and wishes of their administration and members, some groups are partially or wholly anonymised in my work, while most activists have chosen to be partially recognisable to their peers by using their first names or initials. Over the period of my involvement in groups there have been many changes to the technological affordances of Facebook, some of which I reference further in the article. These have impacted on the development and maturing of some forms of lactivist action, but also changes to the status, numbers, makeup, and engagement in action in specific groups, the details of which are beyond the scope of this article.

What this extended period of observation, interviews and exchanges in the field allowed me to understand is the way in which participation in groups engages breastfeeding parents on an embodied level by capturing our selves, senses and emotions, based on the organising principles of sharing and presence. While this article goes on to chart the forms of sharing that involve objects, information and knowledge, within groups breastfeeding parents are also sharing in the heartbreak and in the triumphs of others who manage to breastfeed despite negative comments from friends, family and healthcare professionals. The frequency of representations of breastfeeding used within group 'spaces' is another way in which embodiment is part of the online mundane (cf. Ferreday 2009, Tiidenberg 2015).We share pictures of ourselves breastfeeding our children ('brelfies'), experiencing the pleasure and navigating the exposure this kind of sharing can bring, including anger and fear of charges of ‘indecency' (cf. Boon and Pentney 2015, Giles 2015, Tiidenberg 2016). We can also be 'vicariously traumatised' (Pearlman 1995) by the experiences of others: death of a fellow member's child, reports of neglect, abuse, illness or stories of birth trauma. The complexities of 'translations' of self into social media spaces (Rudnicki 2017) are also premised on presence - being 'on' for the night feeds, tapping away to fellow night-feeders with one hand, whilst nursing a child. Presence in a group is therefore experienced and performed on a personal, intimate level, but also 'done' in public ways.

As L.T. Taylor (2002) argues, 'presence is one of the most elusive and evocative aspects of virtual systems' - an integral part of the 'immersion' and of being 'in' a space/environment that users of mediated environments experience, one that "goes to the heart of what feels "real"" (42). Feminist researchers of online communities remind us that online exchanges and 'presences' are not distinct and separate from the users/members daily lives: Radhika Gajjala 
(2002) points to 'embodied negotiation' of discursive spaces and the interconnectedness of online communities and off-line materialities, while Adi Kuntsman notes that 'words in cyberspace [...] are never "just words"' $(2009,25)$. A sense of 'being there' and of 'being there for each other' are within the spaces of Facebook groups crafted through words - posts, comments - and an increasing repertoire of other expressive, technologically facilitated, mostly visual inputs: reactions ('likes', 'loves', and 'anger'), stickers, memes and gifs ${ }^{6}$. From the many emotionally charged exchanges that occur online and from this elusive sense of presence a notion of 'togetherness' may emerge (cf. Bergh 2017), through which spaces of sharing and support focused on practice and experience may lead to politicised engagements, which blur the boundaries between activism, protest, advocacy, and hegemonic knowledge negotiations (Akrich 2010). This article looks, in turn, at the ways in which lactivists on Facebook craft both the support and the activism with the use of capabilities present within the social media platform.

\section{In-group support}

Breastfeeding support groups are vital resources for living with a 'health conundrum' that the dyadic breastfeeding embodiment poses, and in this sense are both similar to, and different from, typical patient (health problem) groups. Like other groups, Facebook breastfeeding groups are primarily spaces of support, in which informational and instrumental support are inextricably linked with affirmation and emotional support parents receive (Mecinska 2018, 2018 a, cf. Lin and Bhatacharjee 2009, Fredriksen et al. 2016, Drentea and Moren-Cross 2005). The 'knowledge base' on breastfeeding (Boyer 2011) - research on human milk and lactation - is used to learn to live as a breastfeeding body and turned by group members into practical, actionable know-how (Pols 2013). Biomedical knowledge on breastfeeding is also used by lactivist to justify and defend the practice (cf. Faircloth 2013, Hausman 2003), bolstered by technologically-facilitated knowledge dissemination, using pictorial content (memes, infographics) and mediated connectivity, which allows for breastfeeding knowledge to be circulated quickly and efficiently.

One example of this is the stomach size meme ${ }^{7}$ (Fig.1), which ranks amongst the most frequently shared lactivist images, using comparisons with fruit, marbles, or sweets to visualise the size of a newborn infant's stomach. Its widespread use in online forms of breastfeeding activism - in groups, but also by pages and blogs - attests to a synergy between content (easy to read, pictorial information) and its digital format (easy to duplicate, copy, forward, and

\footnotetext{
${ }^{6}$ Respectively: small, colourful character-based images used to convey emotion or thoughts, image or textbased typically humorous visuals designed for sharing, and moving images in Graphic Interchange Format

${ }^{7}$ The accuracy of calling it a meme may be questionable, yet this is what groups call it.
} 
access on mobile and hand-held devices). Typically posted as a comment or relayed in a 'PM' (private message), the swiftness of reply and the ease of re-posting are crucial, if the information is to reach a person pressurised to use formula to supplement. This is an example of knowledge rendered in an accessible way, shared between members as information and instruction, but also to reassure first-time breastfeeders that they are producing enough milk to feed their infant. As digital artefacts 'memes' are also manipulable - easy to adapt, edit and (re)produce in different linguistic versions, another aspect of importance across different contexts of lactivism.

Figure 1: Variants of stomach size meme (authors: unknown, unknown, unknown, blizniaki na piersi)
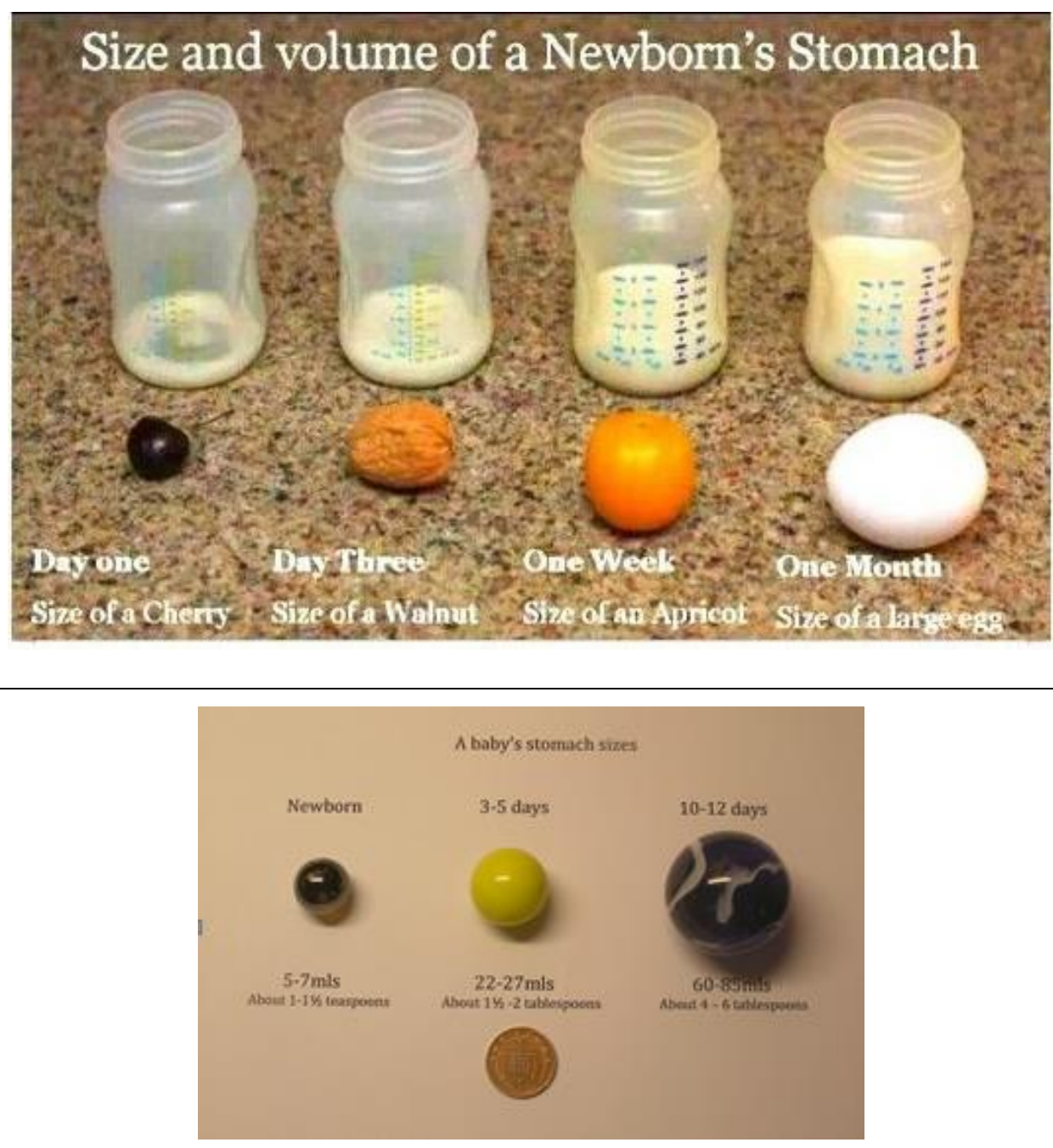


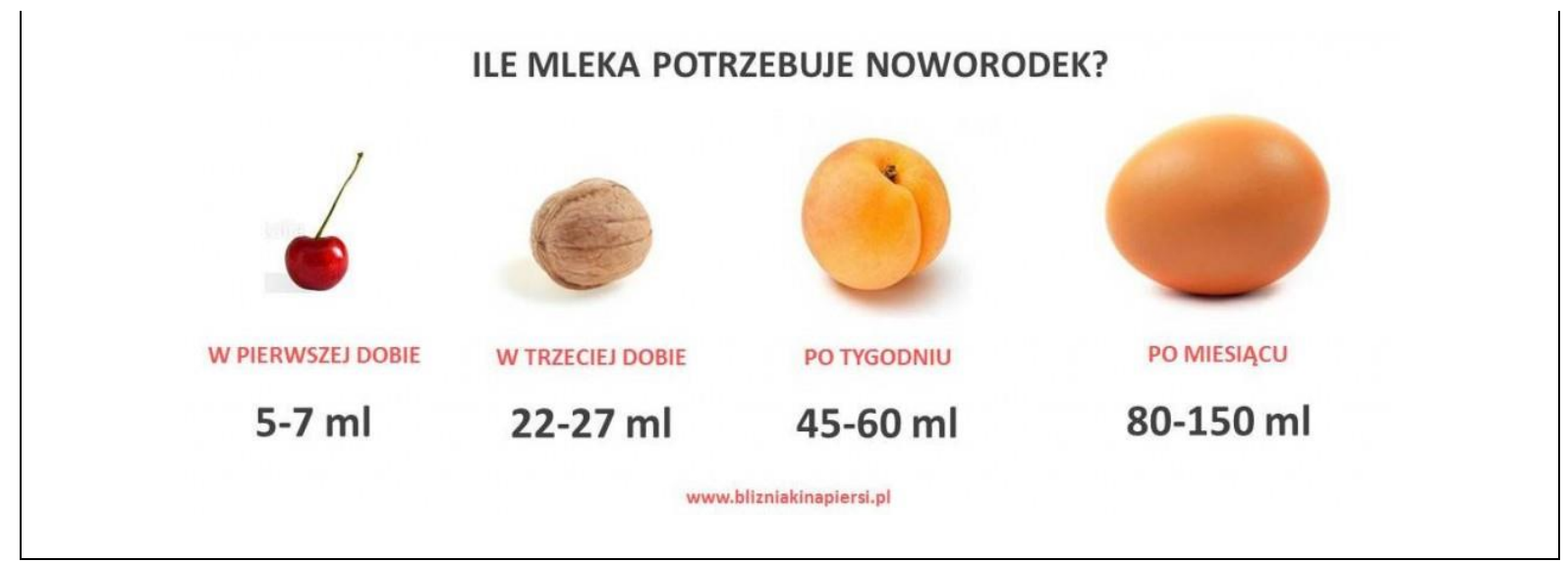

A related tactic used by lactivists is having a collection of 'handy' memes and 'useful' links. It represents the less-visible aspect of lactivism that is the mundane work of knowledge building and support in a digital environment. Within Facebook groups searching for relevant information about breastfeeding may also involve searching the group's 'docs' collated by members/admin, or using the built-in search tool ('spy glass'). Such knowledge elements are then put to different uses in a wider politico-cultural environment which prioritises individual responsibility for health (Mecinska 2018a). A fairly common practice, this way of creating own 'stores' of 'research' for easy dissemination resonates with studies on collating and circulating of health information more broadly (Nettleton et al. 2004). It can be argued, therefore, that the specific effectiveness of knowledge-based support offered is facilitated by the specific technological capabilities of Facebook. Through the use of its tools - groups, image and document sharing, searches, and private messaging - lactivists are swiftly disseminating argumentation related to breastfeeding, which can be used to their advantage outside the groups. In this sense, the internal (support) and external (activist) functions of groups are inextricably linked, with the actions of the support group serving as a crucial space for creating awareness of the importance and value of breastfeeding (Mecinska 2018a) and further for lactivist mobilisation, to both Facebook-specific and 'spillover' actions. In order to understand the lactivist 'repertoire of contention' (Tarrow 2006), forms of joint and mass action performed on Facebook are considered, before moving to forms staged externally, which nevertheless remain connected to Facebook spaces.

\section{Everyday electronic contention}

The 'tactics of electronic contention' (Costanza-Chock 2003) employed by lactivists cover 'conventional' work of augmenting and facilitating off-line movement organising. From the distribution and gathering of information and research, through artistic production, online petitioning, and fundraising, to representation through Facebook walls and groups. But it is the 'visible' actions that are popularly recognised as lactivism. These may be the kinds of actions labelled 'disruptive' (Costanza-Chock 2003) - virtual sit-ins, increases of traffic to sites 
resulting in denial of service (temporary removal), alterations of sites expressing opposing views, and email or form floods - or borderline, like the coordination of offline protest through online means. Taking this categorisation as a starting point, chosen forms of 'electronic contention' performed by Facebook lactivists are considered here.

Some forms of disruptive online tactics require considerable technological savvy, but lactivist variants on Facebook have a low threshold for participation. Rather, my observation demonstrates that lactivists seem to be swiftly making use of tools available on Facebook. For example, alterations to 'walls' have been made easier through the 'report a correction' feature. Using this function lactivists blocked from commenting and engaging in debate on a 'bingo, 8 wall repeatedly corrected the erroneous claims made in its public posts (07/17). Similarly, the function of 'rating' business pages facilitates 'negrating', or negative rating of pages representing businesses deemed to be discriminating against breastfeeding women or expressing negative views on breastfeeding. A coordinated mass action, negrating involves posting negative ratings and reviews on the offender's wall and bringing its rating down using Facebook's star system. Negrating aims to negatively impact the reputation of an organisation (reputational damage). Both of these direct and disruptive forms of action are perceived from within the movement as 'defence' and as an 'adjustment' or 'corrective' measure, but may be interpreted by the affected entities (and their followers) as a (coordinated) 'attack'. What matters here, is the ease with which members alerted through a group engage in direct action.

\section{Visualising and verbalising reproach}

Related forms of action involving increases in traffic and engaging in a discursive 'rectification' effort are closely linked to the everyday lactivist monitoring of the effectiveness of protective legislation stemming from the International Code of Marketing of Breast-milk Substitutes (Code) (WHO 1981, Shubber 2011). Evidence of Code breaches might be posted to the offending entity's Facebook pages, and re-posted in a group, as photographs or screen captures of activities prohibited under the Code, such as promotions at point of sale (Fig. 2) or specific advertising copy sighted by a lactivist. This propels other members to comment on the offender's page and report back on the issue within the group. Comments posted by Facebook users on company pages are visible to their friends, to other Facebook users connected to that page, and to others commenting on the item. Thus, posting an image is a form of visualised evidential reproach, targeted at an entity and involving charges of perceived wrongdoing or misinformation. Reproachful evidence is here a disruption of the company's communication

\footnotetext{
${ }^{8}$ A business-backed quasi-NGO
} 
and a way of changing the contents of its page, bringing to public awareness the possibility of breaking the law.

\section{Figure 2: Evidence of Code breaking through promotion of first stage substitute milk at POS in images posted by a UK-based Facebook group members}
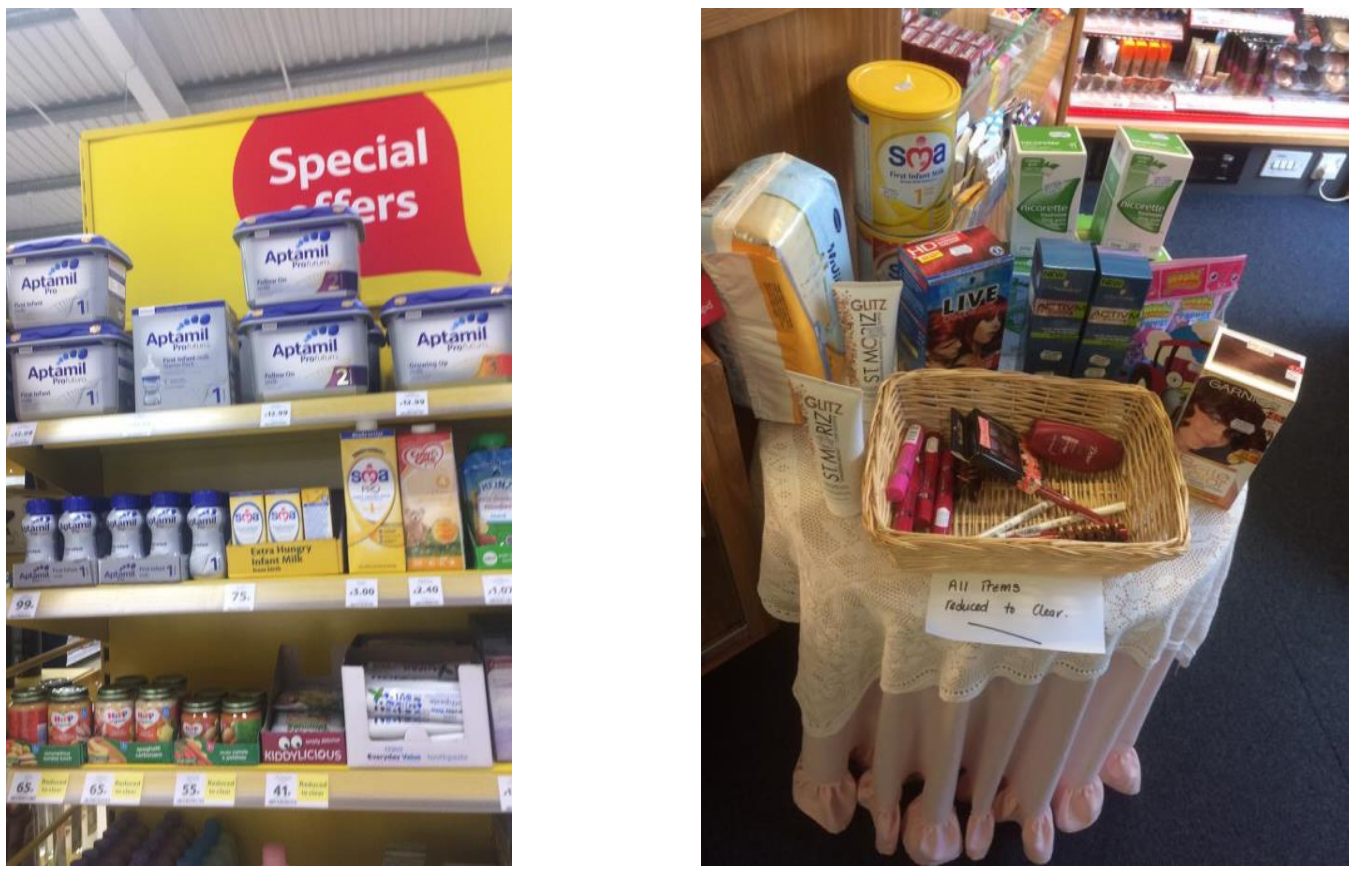

Reproach might also be verbalised against companies breaking the Code based on their advertising copy. Verbalising, an individual Facebook user will address another entity directly or by 'tagging' them in a post on their own wall, to correct an instance of misinformation or a 'mistake'. An example of this is Lucy, a lactivist and member of several UK-based groups, addressing Nestlé:

Hello Nestlé! Just a concern I've got about your ability to "research advancing baby nutrition" over the last 90 years without seeming to understand how breastmilk is made... the adverts you funded last year seem to suggest that breast milk is directly derived from food... it's not. It's synthesised from blood not burgers, here's a link for your scientists, it should explain it fairly easily [...] $(30 / 06 / 16)$

Lucy uses sarcasm as a way to upset the company's chosen communication and she also provides the company with a link to a lactivist website, at once addressing manufacturer's misinformation campaign and popularising lactivist knowledge resources. Importantly, targeting Nestlé is also part of one of the longest standing (and growing) consumer boycotts, initiated by breastfeeding activists nearly 40 years ago (Van Esterik 1989, Palmer 2009). 
Reproaches may turn into calls for a boycott, as was the case during the Dove campaign in the summer of 2017. Dove's advertising copy read '75\% say breastfeeding in public is fine, $25 \%$ say put them away' which quickly led to reproach from the lactivist community interrupting Dove's intended message and communication. Dove was further seen as responding inadequately to the reproach, as evidenced by comments to its statement on Facebook (04/07/17) using a hashtag calling for consumer action (\#doveboycott). Reproaches may be framed as a consumer 'intervention' or aimed at 'corporate responsibility', but their main function is to gain visibility for lactivist opposition to specific law-breaking, unethical, harmful, or misleading corporate practices. It has been suggested that consumer boycotts launched by individuals on the internet are ineffective in inflicting economic harm on the targeted firm (Koku 2011, 2012), but the activist counter is that a sustained action may prove effective 'if the aim is to undermine companies that stand in the way of a movement' (Reed 2017). Important here, is the way these actions are grounded in the mundane orientations of the lives of the individuals who initiate them, and the way in which they use mediatised projections of their voice and their sight, their very embodied senses, in constructing the reproach.

The ways in which such individual interventions are then multiplied through specific technological means by lactivists whose mutual allegiance grows out of a sense of commonality predicated on engagement in an embodied practice of breastfeeding, is equally important for understanding the role of embodiment in online activism. Actions which use social media technologies in similar ways, like metadata tagging to raise awareness of an issue (hashtags) or documentation of transgressions and harassment (hollabacks), are not uniquely lactivist and have been used across social media (Ferreday 2017, Pearson and Trevisan 2015). Some critics see these forms of action as less effective than activists assume: as a result of their immersion in mediatised environments, social media activists over estimate the effect of these interventions in the world outside the 'mediatised bubble' (Nagle 2013). Yet privileging 'real life' action may make little sense in a world where online interactions are inextricably interwoven in the fabric of our daily lives. Furthermore, Facebook and off-line actions have a tendency to spillover into one another in ways described below.

\section{Spillovers and visibility}

Facebook pages and groups have certainly facilitated the organisation of forms of embodied activist action involving occupation of public or quasi-public spaces, which then sent ripples across social media. An example here might be the Free to Feed protest organised outside Claridge's Hotel in London in response to the upmarket establishment's unfavourable treatment of a breastfeeding woman (cf Mecinska 2018). It started with a tweet by the victim 
and resulted in its own hashtag \#OstentatiousBreastfeeding. The action of occupying a space, as performed by the women outside Claridge's, forces the spectators to confront 'latent and overt assumptions about motherhood in relation to parenting proficiency, civic responsibility, maternal sexuality, and political efficacy' (Carpenter 2006, 348). Such performances of breastfeeding frame the act as an agential, representational activity, which troubles 'the archaic notion of the breastfeeding mother as an iconic symbol of subservient, home-bounded domesticity' (350). Here, 'holding a public event in which breastfeeding is specifically supported and encouraged' is a way to 'seek to change norms around how urban space is understood', an effort to expand the boundaries of where care-work is allowed to take place (Boyer 2011, 434).

The visibility and 'spectacle' of group nursing is staged with the aim of creating 'a public forum as a conduit for social transformation' (Carpenter 2006, 350). Exposure has a double meaning in relation to such lactivist actions: exposing the breast and creating a conscious display of breastfeeding, one which can subsequently be re-enacted through social media representations. The desired effect is to affect the audience and social media allow lactivists to organise these and make them visible to wider audiences. Because of this, lactivists consciously stage, perform, document and then use social media to re-enact nursing-in-public (NIP) through images shared online (Fig. 3). These visuals are tied to the individual and collective experiences of staging embodied lactivist protest, and have the potential to 'carry' these embodied practices through to the online realm (Bergh 2017). Visibility is a crucial motivator for those who advocate for NIP, as research suggests that 'embodied knowledge gained from seeing breastfeeding' is most likely to positively influence decisions to breastfeed (Hoddinot and Pill 1999). Breastfeeding, as a bodily capability, is developed (learned) through observation of how others fulfil it in the conditions of a given society; when breastfeeding women are removed from public space, an aspect of intergenerational and peer learning vanishes. Similarly to group nursing, NIP is increasingly framed within lactivist groups as a one person intervention aimed at 'normalising' breastfeeding. The tactical deployment of such practices is based on an interconnectedness of speaking, thinking and doing (de Certeau 1988, 79).

When NIP-ing and documenting NIPs in brelfies lactivists reveal bodies that do not fit 'the narrow standards' of 'consumer culture's norms of appearances' and not 'easily commodifiable' (Tiidenberg and Gómez-Cruz 2015, 15). Brelfies are frequently met with outpourings of hostility and misogyny, and lactivist spaces are often centred on an awareness of becoming an object of abjection (Kowalczyk 2010). This further underscores the embodied politics of doing breastfeeding as 'doing the taboo thing' (Boyer 2011). Lactating bodies engaged in NIP in this sense speak to Rebecca Coleman's 'bodies as becoming' (2008), not 
limited to body and image, but imbued with, and seeping into, daily practice and politics. In this context women's embodied practice of breastfeeding projected and augmented using social media becomes a movement tactic, a daily mass action, an embodied and sustained opposition to the denigration voiced by detractors.

\section{Figure 3: Documenting and sharing NIP (UKBAPS, KCNU, UKBAPS)}
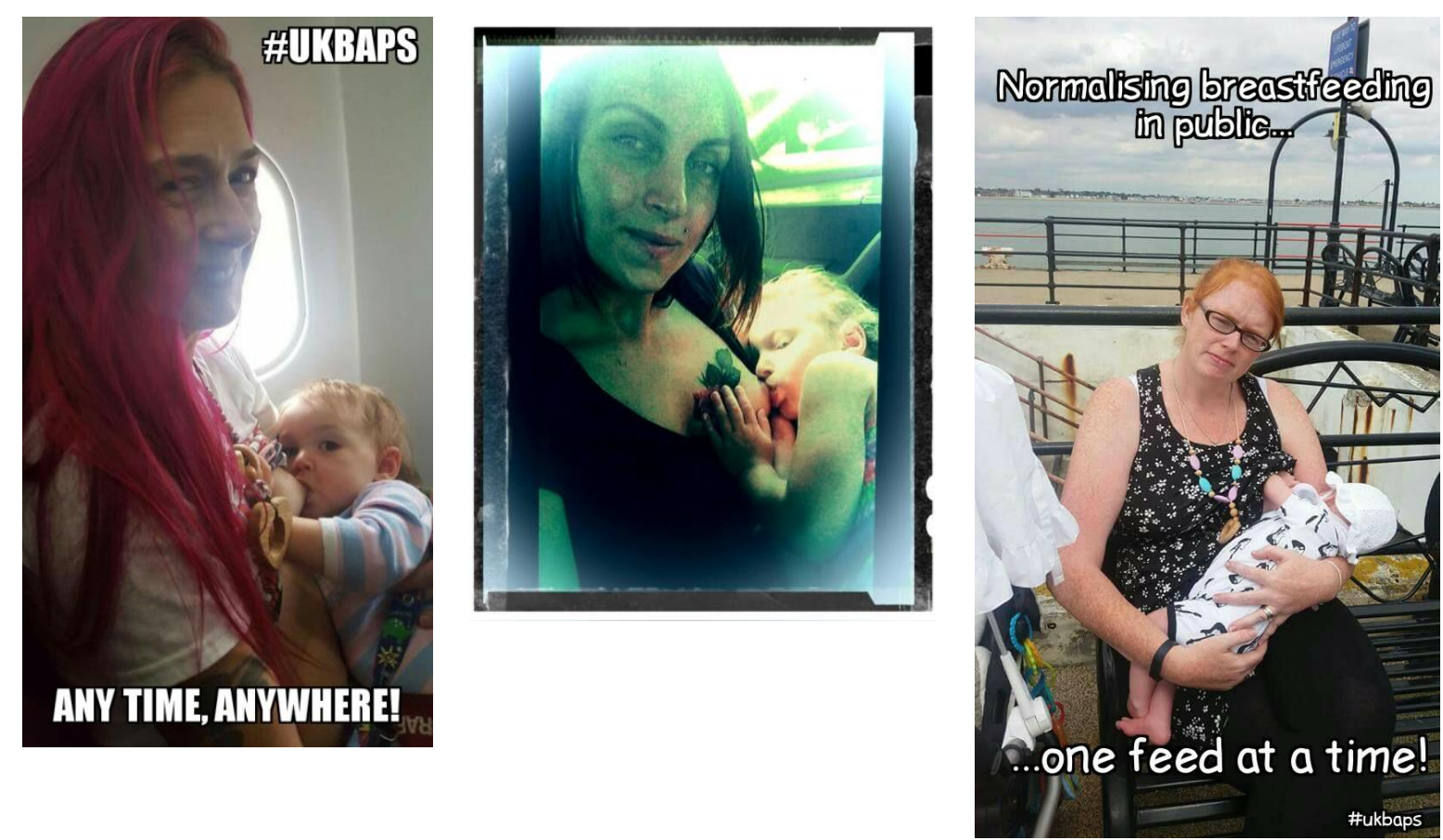

\section{Lactivism as we know it}

The instances I describe here do not exhaust the types of actions and activities that lactivists on Facebook and other social media platforms and online environments undertake. They reveal, however, the ways in which lactivists' doing of politics and doing of intimacies with and through their devices is shaping lactivism. Participation in online groups is often practiced side-by-side with breastfeeding, with many of the women I spoke to describing it as being 'on the bed feeding, on the laptop'. This reminds us that, as Hine suggests, the ways in which the online world 'is embedded into our lives' is partly made through our embodied engagement(s) with it and that, in turn, these engagements 'can shape our experience of embodiment as the information and insights we find online help us to understand ourselves in new ways' (2015, 24). The transformative potential of being/feeling part of something through such embodied engagements, which for lactivists on Facebook happens both in groups and in the forms of action, resonates with literature on social movement participation (Taylor and Leitz 2010, Shrock et al. 2004, Bergh 2017). In instances such as those described above, mutual support, group cohesion and commonality based on the embodied practice of breastfeeding may be 
expressed by 'liking', otherwise reacting, or commenting on a post by a 'fellow breastfeeding mama'. Moreover, media have become 'infrastructures of intimacy' and connections are now formed not only with other people, but with 'devices, apps and platforms' (Paasonen 2018, 104). The forms of action facilitated by the specific technological infrastructure of Facebook and the activities of lactivist groups within its specific landscape are intertwined with the intimate connections between 'wise ladies on my phone' and our intimacies. Through mass actions involving posting of brelfies or documenting NIP lactivism has also shaped the medium. Facebook used to routinely remove breastfeeding images and users who shared such images risked having their accounts suspended or deleted (cf. Lunceford, 2012), but following considerable pressure by lactivists Facebook had to acknowledge that sharing breastfeeding images is not a violation of its 'community standards' and does not represent obscene material. Repeated posting of the same type of imagery purposefully risking being 'banned' by Facebook, also demonstrates the ways in which tactics used by lactivists are based on 'ethics of tenacity' (de Certau 1988, 26) - unrelenting devotion to what is seen as 'just'. Feona Atwood, Jamie Hakim and Alison Winch $(2017,250)$ note that while the sphere of the intimate 'excites considerable fascination and attention', it is seen at present as 'relatively unimportant within the wider scheme of political and public life', due in part to the division between the 'capitalist sphere of production and the site of social reproduction'. Doggedly intruding the public with the embodied practice of breastfeeding and a politics rooted in an allegiance to others who engage in it, lactivism seems to be (re)politicising the intimate.

\section{References}

Aiken, A. and Thomson, G. (2013) 'Professionalization of a breast-feeding peer support service: Issues and experiences of peer supporters', Midwifery, 29, 45-51.

Akrich, M. (2010) 'From communities of practice to epistemic communities: Health mobilizations on the internet', Sociological Research Online, 15(2).

Attwood, F., Hakim J. and Winch, A. (2017) 'Mediated intimacies: bodies, technologies and relationships', Journal of Gender Studies, 26(3), 249-253.

Bergh, S. (2017) 'Techinques of Mobilisation: Dialectic Development of Sharedness through Virtual and On-The-Ground Practices', Visual Ethnography Journal, 6(1).

Boon, S. and Pentney, B. (2015) 'Virtual Lactivism: Breastfeeding Selfies and the Performance of Motherhood', International Journal of Communication, 9(14), 17591774.

boyd, d. (2010) 'Social Network Sites as Networked Publics: Affordances, Dynamics, and Implications', in Z. Papacharissi (ed), Networked Self: Identity, Community, and Culture on Social Network Sites, London: Routledge, pp. 39-58. 
Boyer, K. (2011) "'The way to break the taboo is to do the taboo thing" breastfeeding in public and citizen-activism in the UK', Health and Place, 17(2), 430-437.

Brown, P., Zavestoski, S., McCormick, S., Mayer, B., Morello-Frosch, R. and Gasior Altman, R. (2004) 'Embodied health movements: new approaches to social movements in health', Sociology of Health and IIIness, 26, 50-80.

Carpenter, F.Ch. (2006) '“Lactivists and Lattes”: Breastfeeding Advocacy as Domestic Performance', Women and Performance: A Journal of Feminist Theory, 16(3), 34767.

Coleman R. (2008) 'The becoming of bodies', Feminist Media Studies 8(2), 163-179. Costanza-Chock, S (2003) 'Mapping the Repertoire of Electronic Contention', in A. Opel and D. Pompper (eds), Representing Resistance: Media, Civil Disobedience and the Global Justice Movement. NJ: Greenwood, pp. 173-191

De Certeu, M. (1984) The Practice of Everyday Life. London: University of California Press

Dowling, S. (2014) Exploring the experiences of women who breastfeed long-term. PhD, University of the West of England.

Drentea, P. and Moren-Cross, J.L. (2005) 'Social capital and social support on the web: the case of an internet mother site', Sociology of Health and IIIness, 2005, 920943.

Epstein, S. (2008) 'Patient groups and health movements', in E.J. Hackett, O. Amsterdamska, M. Lynch and J. Wajcman (eds), The Handbook of Science and Technology Studies, Massachusetts: MIT Press, pp. 499-538.

Faricloth, C. (2013) Militant Lactivism? Intensive Motherhood and Attachment Parenting in the UK and France. Oxford: Berghahn

Ferreday, D. (2009) Online Belongings: Fantasy, Affect and Web Communities. Bern: Peter Lang.

Ferreday, D. (2017) 'Something substantive enough to reach out and touch: the intimate politics of digital anti-rape activism' in R. Andreassen, M. Nebeling Petersen, K. Harrison, T. Raun (eds), Mediated Intimacies: Connectivities, Relationalities and Proximities, London: Routledge, pp. 19-32.

Fredriksen E.H., Harris J. and Moland K.M. (2016) 'Web-based Discussion Forums on Pregnancy Complaints and Maternal Health Literacy in Norway: A Qualitative Study', Journal of Medical Internet Research, 18(5).

Gajjalla, R. (2002) 'An Interrupted Postcolonial/Feminist Cyberethnography: Complicity and Resistance in the "Cyberfield"', Feminist Media Studies, 2(2), 177-193.

Giles, F. (2015) 'Breastfeeding as a social activity. The role of brelfies in breastfeeding's burgeoning publics', ESRC Breastfeeding Seminar Series. Available at:

http://www1.uwe.ac.uk/hls/research/healthandclinicalresearch/seminarseries/semina rschedule/seminar5.aspx 
Greiner, T. (2000) 'The history and importance of the Innocenti Declaration', keynote at Allattamento e Politiche per I'Infanzia Dieci Anni dopo la "Dichiarazione degli Innocenti"

Hausman, B. L. (2003) Mother's milk: Breastfeeding controversies in American culture. London: Routledge.

Hausman, B.L. (2004) 'The feminist politics of breastfeeding', Australian Feminist Studies, 19(45), 273-285.

Hine, C. (2000) Virtual Ethnography, London: SAGE.

Hine, C. (2015) Ethnography for the Internet: Embedded, Embodied and Everyday, London: Bloomsbury.

Hoddinott, P. and Pill, R. (1999) 'Qualitative study of decisions about infant feeding among women in East End of London', BMJ, 318(7175), 30-34.

Kedrowski, K. (2010) 'Women's Health Activism in Canada: The Cases of Breast Cancer and Breastfeeding' Canadian Political Science Association Meeting Montreal, QC. Available at: https://www.cpsa-acsp.ca/papers-2010/Kedrowski.pdf

Koku, P.S. (2011) 'On Boycotts Organized Through the Internet', Journal of Marketing Development and Competitiveness, 5(6), 83-93.

Koku, P.S. (2012) 'On the effectiveness of consumer boycotts organized through the internet: the market model', Journal of Services Marketing, 26(1), 20-26.

Kowalczyk, I. (2010) 'Bryzgajace' piersi'. Straszna sztuka http://strasznasztuka.blox.pl/2010/01/Bryzgajace-piersi.html

Kuntsman, A. (2009) Figurations of violence and belonging: Queerness, migranthood and nationalism in cyberspace and beyond, Oxford: Peter Lang.

Labbok, M. (2015) 'The Gloobal Village: Do Women Live There?' in P.H. Smith and M. Labbok (eds) It Takes a Village: The Role of the Greater Community in Inspiring and Empowering Women to Breastfeed, Amarillo, TX: Praeclarus Press, pp. 23-31.

Landzelius, K. (2006) 'Patient Organisation Movements and New Metamorphoses in Patienthood', Social Science and Medicine, 62(3), 529-37.

Leune, A.S. and Nizard, J. (2012) 'Docteur Google : l'utilisation d'Internet au cours de la grossesse en France, en 2009', Journal de Gynécologie Obstétrique et Biologie de la Reproduction, 41(3), 243-254.

Lin, Ch.P. and Bhattacherjee, A. (2009) 'Understanding online social support and its antecedents: A socio-cognitive model', The Social Science Journal, 46, 724-737.

LLLI (2012) A Brief History of La Leche League International [online]. Available at: http://www.Illi.org/llihistory.html

Lunceford, B. (2012) 'Weaponising the Breast: Lactivism and Public Breastfeeding', in Naked Politics: Nudity, Political Action, and the Rhetoric of the Body. Plymouth: Lexington. 
Maltby, S. and Thornham, H.M. (2016) 'The digital mundane: social media and the military', Media, Culture and Society, 38(8), 1153-1168.

McDaniel, B.T., S.M. Coyne and Holmes, E.K. (2012) 'New mothers and media use: associations between blogging, social networking, and maternal well-being', Maternal and Child Health Journal, 16, 1509.

Mecinska, L. (2018) Social struggles over breastfeeding: how lactivism reshapes knowledge, meanings, and practices of breastfeeding, PhD, Lancaster University.

Mecinska, L. (2018a) "Milk Pride': Lactivist Online Constructions of Positive Breastfeeding Value', Studies in the Maternal, 10(1) DOI: http://doi.org/10.16995/sim.258

Moeran, B. (2007) 'From Participant Observation to Observant Participation: Anthropology, Fieldwork and Organizational Ethnography', Creative Encou7nters Working Paper.

Nagle, A. (2013) 'Not quite kicking off everywhere: feminist notes on digital liberation', in C. Fowley, C. English, S. Thouësny Internet research, theory, and practice: perspectives from Ireland,,Dublin Research Publishing, pp 157-175.

Nettleton, S. Burrows, R. and O'Malley, L. (2005) 'The mundane realities of the everyday lay use of the Internet for health, and their consequences for media convergence' Sociology of Health and IIIness, 27(7), 972-992.

Palmer, G. (2009) The Politics of Breastfeeding, London: Pinter and Martin.

Pearlman, L. A. (1995) 'Self-care for trauma therapists: Ameliorating vicarious traumatization', in B. H. Stamm (ed), Secondary traumatic stress: Self-care issues for clinicians, researchers, and educators, Baltimore, MD: The Sidran Press, pp. 51-64.

Pearson, C. and Trevisan, F. (2015) 'Disability activism in the new media ecology: campaigning strategies in the digital era', Disability and Society, 30(6), 924-940.

Pols, J. (2013) 'Knowing patients: turning patient knowledge into science', Science, Technology and Human Values, 0(00), 1-25.

Radkowska-Walkowicz, M. (2010) 'Nie słuchaj teściowej! Czyli jak żywić niemowlę w czasach Internetu', Antropolog wobec współczesności. Warsaw: leiAK UW.

Reed, A. (2017) 'Social Media Boycotts Succeed When They Reflect a Movement' NY Times https://www.nytimes.com/roomfordebate/2017/02/07/when-do-consumerboycotts-work

Romano, A.M. (2007) 'A Changing Landscape: Implications of Pregnant Women's Internet Use for Childbirth Educators', Journal of Perinatal Education, 16(4), 18-24.

Rudnicki, S. (2017) 'The Body, Technology and Translation: Mapping the Complexity of Online Embodiment', Sociological Research Online, 22(2), 1-13.

Schaffer, R., Kuczynski, K. and Skinner, D. (2008) 'Producing genetic knowledge and citizenship through the Internet: mothers, pediatric genetics, and cybermedicine', Sociology of Health and IIIness, 30(1), 145-159. 
Shubber, S. (2011) The WHO international code of marketing of breast-milk substitutes. History and Analysis, London: Pinter and Martin.

Stearns, C. (2014) 'The Embodied Practices of Breastfeeding: Implications for Research and Policy', Journal of Women, Politics and Policy, 34(4), 359-370.

Tarrow, S. (2006) Power in movement: social movements and contentious politics, Cambridge: CUP.

Taylor T.L. (2002) 'Living Digitally: Embodiment in Virtual Worlds', in R. Schroeder (ed), The Social Life of Avatars: Presence and Interaction in Shared Virtual Environments, London: Springer-Verlag.

Taylor, V. and Leitz, L. (2010) 'From Infanticide to Activism: The Transformation of Emotions and Identity in Self-Help Movements', in J.C. Banaszak-Holl, S.R. Levitsky, and M.N. Zald (eds), Social Movements and the Transformation of American Health Care, Oxford: OUP, pp. 266-284.

Tiidenberg, K. (2015) 'Boundaries and conflict in a NSFW community on tumblr: The meanings and uses of selfies', New Media and Society, 18(8), 1563-1578.

Tiidenberg, K. and Gómez-Cruz, E. (2015) 'Selfies, Image and the Re-making of the Body', Body and Society, 1-26.

Tomori, C. (2014) Nighttime Breastfeeding. An American Cultural Dilemma, Oxford: Berghahn Books.

Torres, J. (2014) 'Medicalizing to demedicalize: Lactation consultants and the (de)medicalization of breastfeeding', Social Science and Medicine, 100, 159-166.

Van Esterik, P. (1989) Beyond the Breast-bottle Controversy, New Brunswick, NJ: Rutgers University Press.

Weiner, L.Y. (1994) 'Reconstructing Motherhood: La Leche League in Postwar America', The Journal of American History.

WHO (1981) International Code of Marketing of Breastmilk Substitutes http://apps.who.int/iris/bitstream/10665/40382/1/9241541601.pdf

Wilson, J.A. and Chivers Yochim, E. (2017) Mothering through Precarity. Women's Work and Digital Media, London: Duke University Press.

Zdrojewska-Żywiecka, A. (2012) 'Terror laktacyjny versus nagonka butelkowa. O konfliktach między kobietami w zakresie praktyk macierzyństwa', in R.E. Hryciuk, and E. Korolczuk (eds), Pożegnanie z Matką Polką?, Warsaw: University of Warsaw Press, pp.125-146.

Lula Mecinska is a feminist and a lactivist, whose main research falls within the interdisciplinary field of breastfeeding studies, with forays into disability studies and criminology. More broadly, she is interested in women's activism, particularly its local, grassroots and online forms. A member of the reproductive justice cross-faculty interest group at the University of Cumbria, where she works, Lula completed her $\mathrm{PhD}$ in Sociology at Lancaster University. She is also an alumna of the Centre for Social Studies Polish Academy 
Networking Knowledge 11(2) Communities and the Media Around the Globe (Dec. 2018)

of Science, the Institute of English Studies at the University of Warsaw, and English and Cultural and Media Studies at University of the West of England, forever indebted to her teachers.

Email: aleksandra.mecinska@cumbria.ac.uk 